\title{
Reconciling Leadership Paradigms: Authenticity as Practiced by American Indian School Leaders
}

\author{
David Henderson \\ Montana State University \\ U. S. A. \\ Jioanna Carjuzaa \\ Montana State University \\ U. S. A. \\ William G. Ruff \\ Montana State University \\ U. S. A.
}

\begin{abstract}
This phenomenological study examined the complexity American Indian K-12 school leaders face on reservations in Montana, USA The study described how these leaders have to reconcile their Westernized educational leadership training with their traditional ways of knowing, living, and leading. Three major themes emerged that enabled these leaders to address racism in their schools and create spaces that were more conducive to the practice of culturally responsive pedagogy. The study highlights how leaders reconcile cultural clashes and confront racism by using identity, relationality, and renormed practices.
\end{abstract}

KEYWORDS: educational leadership, culturally responsive pedagogy, racism, Indian education, social justice

\author{
Conceptual Framework and Context \\ Methodology \\ Findings \\ Implications and Conclusions \\ References \\ Author Contact
}

This phenomenological study examined the cultural complexity faced by American Indian school leaders in K-12 schools located on or near Indian reservations in Montana, a state in the western United States. Although an increasing body of literature is being generated on the topic of Indigenous leadership (Bird, Lee, \& López, 2013; Faircloth \& Tippeconnic, 2013; Grahn, Swenson, \& O'Leary, 2001; Hohepa, 2013; Klug, 2012), scant research exists regarding how American Indian school leaders confront racism in complex 
cultural contexts. These leaders face a spectrum of racist behaviors and practices. For example, these practices and behaviors include everything from blatant racism as evidenced in a staff member's complaint written to the school board stating, "I'm not working for no Indian bi*ch," to micro-aggressions such as the use of American Indian mascots and noble savage stereotypes. Furthermore, unconscious examples of oblivious White privilege are woven into the pedagogy within their schools where teachers highlight historical events from the dominant cultural perspective exclusively. The following questions guided our study:

1. How do American Indian school leaders reconcile Western educational leadership preparation with Indigenous knowledge?

2. How does this reconciliation reflect and model anti-racist educational leadership?

The study's significance lies in the descriptions of how these leaders embrace their Indigeneity in unique ways and use their identity to lead their schools with integrity and authenticity while confronting racism in their schools.

Although there is no consensus as to the proper terminology to refer to the first inhabitants of the North American continent, the terms American Indian, Native, and Indian are used interchangeably throughout this article unless a more specific tribal affiliation is appropriate to share. In contrast, Indigenous is a global term used here to refer more generally to the people originally inhabiting the lands colonized by Europeans between the $15^{\text {th }}$ and $18^{\text {th }}$ centuries.

\section{Conceptual Framework and Context}

Western leadership tends to be linear and incremental in the sense that a person does one thing, then another, until the result sought is achieved; the success of a leader is reaching an end-result efficiently through effective problem solving (Gardner, 1990). Also, the concept of authority is deeply embedded into the Western leadership paradigm (Weber, 1946). In contrast, Indigenous leadership tends to be circular as well as incommensurate with notions of authority. The measure of leadership is not as much about doing as it is about the depth of being - the leader's character defines the degree to which she/he will be followed. Marshall (2009) explained Lakota leadership as setting the example for others to follow: "ordinary people who rise to meet a need or to help achieve a seemingly simple goal" (p. 27). Medicine Crow (2006), a Crow tribal historian and former chief, described becoming a leader as a series of individual acts performed in the course of routine daily activities. Others observe the quality of those routine acts based on tribal values and decide to follow the individual. Thus, a leader is selected by constituents and asserts his or her leadership only as far as he or she has the support of the constituents.

Almost all of the educational leadership programs in the United States approach leadership preparation using leadership constructs derived from the dominant Western paradigm. Similarly, higher education programs in general are 
designed and delivered from a Western, dominant cultural perspective by nonNative faculty. Also, since Indigenous epistemology is distinct from Western epistemology, higher education systems tend to marginalize historically oppressed groups generally, and, in the context of this study, American Indian students specifically (Jaime, 2008; Writer, 2008). In order to address this marginalization, Kirkness and Barnhardt (1991) offered a framework that negotiates inequities empowering Indigenous students to succeed in higher education. Their study focused on the mismatch of perspectives between nonNative faculty and Indigenous students and its effect on pedagogical practices. From this study, they identified four principles for promoting more equitable relationships and interactions between Indigenous students and the academy: respect, relevance, reciprocity, and responsibility - the 4 Rs. To this framework one more principle has been added - relationality (Carjuzaa \& Fenimore-Smith, 2010; Wilson, 2008), thus creating the 5 Rs.

Many Indigenous scholars emphasize the importance of relationships, not just current human relationships but the connection Indigenous peoples have to their ancestors, the future generations, nature, and to the land (Kovach, 2009; Wilson, 2008). Wilson (2008) noted that "the relational way of being was at the heart of what it means to be Indigenous" (p. 80). Deloria stated, in a different way, "We are all relatives" (Deloria, Deloria, Foehner, \& Scinta, 1999, p. 36). Kirkness and Barnhardt's (1991) 4 Rs provided entry to the relationship building process. This relationality creates the space that allows parties to create intimate, on-going relationships and is key to understanding and embracing Indigenous ways of knowing. To better understand Indigenous relationality in a westernized environment, capacities like identity, integrity and authenticity are critical. Wilson (2008) explains that the shared aspect of an Indigenous ontology and epistemology is relationality and that the shared aspect of an Indigenous axiology and methodology is accountability to relationships. In other words, Indigenous identity and ways of knowing are based on relationality. Integrity and authenticity are the means for bringing one's identity to the group, something that is required for meaningful leadership.

The Leadership Triad of identity, integrity and authenticity (Henderson, 2007), an empirically grounded model, explains the dynamic of a leader's identity, integrity and the degree to which others see her or him demonstrating authenticity in leadership. In this model, as leaders deepen their identity and choose with integrity to lead from that identity, this inner-outer congruence informs their ability to lead with authenticity, creating organizations with remarkable relational networks. The first of the model's components is the leader's identity, which is a deeply held understanding of her or his inner self; it is more than just her or his value system or taught norms that transcends cognition and is more akin to what could be called the leader's soul, heart, or true self. The second component is integrity, which is the conscious decision of the leader to let this identity be known in her or his leadership. The third component, authenticity, is the collective of attributes and behaviors the administrator models in leading the school(s), such as relationality, listening, collaborative leading, and humility. 
The model articulates that a leader's inner identity and that leader's outer life can be incongruent. This inner and outer disconnect can result in what Parker Palmer $(2004,2000)$ and others (Thompson, 2000) have described as a "divided self." The model also suggests that one's identity will reveal itself in outer behaviors despite one's best effort to conceal aspects of who one is; this intentional disconnect between the leader's inner life and leadership can result in inauthenticity and damage to followers (Henderson, 2007; Palmer, 2000). This willingness to live and lead from within enables leaders to approach racism in two important ways: leaders will be more grounded in their own identity, both gifts and limitations, and, in so doing, stay in relationship with humility and compassion with those who are struggling to recognize their own limitations from which racism often stems. Also, in maintaining relationships and recognizing the subtlety of racism and the unconscious behaviors of privilege, these leaders are willing to address these behaviors that plague the schooling context and diminish the identity of their Indigenous students.

Using this model as a conceptual tool to examine the active resistance to racism by American Indian school leaders on both an organizational and an individual level provided the means to explore the integration of identity as experienced by the participant and its impact on daily leadership tasks. Organizations, like individuals, can have a racist orientation. In addressing organizational racism, these Indigenous leaders seek to move their school communities across the spectrum from a monocultural, exclusive school to an anti-racist, multicultural, inclusive school (Jackson \& Hardiman, 2010).

In order to set the stage for explaining the findings of this study, it is important that the context in which these school leaders serve be briefly explained. In 1972 the Montana Constitution was amended, recognizing the distinct and unique cultural heritage of American Indians and the preservation of their cultural integrity (Mont. Const. art. X, §1). In 1999, HB 528 established the Indian Education for All (IEFA) initiative, which affirmed the state's commitment.

To guide the implementation of IEFA, the Office of Public Instruction brought together representatives from all the tribes in Montana to create the Seven Essential Understandings that form the framework for curriculum and professional development (Montana Office of Public Instruction, 2014). In this article we focus on Essential Understanding 2, which asserts that there is no generic Indian and, in fact, that great diversity exists among individual American Indians ranging from assimilated to traditional. Also, when a mismatch between the home and school culture occurs, students may have a difficult time seeing themselves reflected in the school curriculum, policies and practices. Educators must value students' cultural heritages and validate their life experiences so all students have an opportunity to reach their academic and social potential (Klug \& Whitfield, 2003).

In our schooling context in Montana, our American Indian population is our largest minority group at approximately $7 \%$ of the total population. However, it is important to note that $14 \%$ of the state's K-12 population is Native, a number 10 times the national average. In addition, the school personnel are still 
predominantly non-native; only $2.68 \%$ of the teaching corps is Native (OPI, 2014). Also, when the participants in this study began their educational leadership program in 2007, there were approximately 12 Native school leaders statewide; today despite a huge improvement in this number (now approximately 100 Native school leaders statewide) these participants remain an isolated minority (Henderson, Ruff \& Carjuzaa, In Press).

\section{Methodology}

In this phenomenological study, we explored the lived experiences of American Indian principals and superintendents working in school systems on or near Indian reservations in Montana. The design used the Leadership Triad described above as the phenomenological lens. Ten school leaders were purposefully selected based on three criteria. First, all participants were American Indian educators who graduated from the Indian Leadership Education and Development (ILEAD) project at Montana State University, an innovative, culturally responsive school leadership preparation program (see Henderson, et al., In Press; Ruff \& Erickson, 2008). Second, each participant served as a school principal or superintendent for at least two years in a public school in an American Indian community. Third, participants led schools where more than $50 \%$ of the students were American Indian and the majority $(>50 \%)$ of the teachers were non-native (with the exception of one school where 41 out of 50 teachers/staff were Native).

The authors conducted all aspects of the research in this study. In addressing positionality, each of us is non-Native faculty in a university town more than 200 miles from the nearest Indian Reservation. We have been engaged in research related to social justice and educational equity for at least five years, taught social justice leadership courses, and have been working with American Indian educators in Montana for 3, 9, and over 20 years respectively. In terms of our experience with racism, it is fair to say that we understand the academic concept through multiple lens; we have each vicariously experienced instances of racism toward American Indians in many forms from both direct observation as well as from stories told by American Indians from many different tribes. Yet, we each continuously find ourselves fighting the assumptions embedded in our lived experience of White privilege.

\section{Participants}

Of the 10 participants, seven were female, three were male and all were enrolled in or descendants of a total of eight different tribal nations. Six leaders served in schools within their home tribal community. Their schools ranged in enrollment from 75-843 students with varying proportions (50-100\%) of American Indian students. For this study, pseudonyms were used for participants' names, 
and tribal affiliations were omitted to ensure participants' anonymity. See Table 1, Participants' Demographics below.

Table1.

Participants' demographics

\begin{tabular}{|c|c|c|c|c|c|c|c|c|}
\hline $\begin{array}{c}\text { Partici- } \\
\text { pant }\end{array}$ & $\begin{array}{c}\text { Gen- } \\
\text { der }\end{array}$ & $\begin{array}{c}\text { Years as } \\
\text { Educator }\end{array}$ & $\begin{array}{c}\text { Years } \\
\text { as } \\
\text { Admin- } \\
\text { istrator }\end{array}$ & $\begin{array}{c}\text { Years } \\
\text { as } \\
\text { Admin- } \\
\text { istrator } \\
\text { in } \\
\text { Current } \\
\text { School }\end{array}$ & $\begin{array}{c}\text { Serves in } \\
\text { a School } \\
\text { in Their } \\
\text { Home } \\
\text { Com- } \\
\text { munity }\end{array}$ & $\begin{array}{c}\text { \# of } \\
\text { \# of } \\
\text { Students } \\
\text { in } \\
\text { Current } \\
\text { School }\end{array}$ & $\begin{array}{c}\text { American } \\
\text { Indian } \\
\text { Students } \\
\text { who are } \\
\text { American } \\
\text { Indian } \\
\text { TeachersI } \\
\text { Staff in } \\
\text { School } \\
\text { (Total \# of } \\
\text { TeachersI } \\
\text { Staff in } \\
\text { school) }\end{array}$ \\
\hline Cathy & $\mathrm{F}$ & 10 & 13 & 2 & No & 130 & $99 \%$ & $12 / 5(30)$ \\
\hline Rosie & $\mathrm{F}$ & 13 & 2 & 2 & Yes & 350 & $80 \%$ & $2 / 4(45)$ \\
\hline Lucy & $\mathrm{F}$ & 34 & 8 & 2 & Yes & 144 & $100 \%$ & $6 / 7(28)$ \\
\hline Jake & $\mathrm{M}$ & 14 & 7 & 1 & Yes & 294 & $100 \%$ & $12 / 22(54)$ \\
\hline Shawna & $\mathrm{F}$ & 11 & 3 & 3 & No & 75 & $95 \%$ & $1 / 1(20)$ \\
\hline Josie & $\mathrm{F}$ & 14.5 & 4 & 2 & Yes & 298 & $99 \%$ & $35 / 6(50)$ \\
\hline Shelly & $\mathrm{F}$ & 12 & 4 & 4 & No & 350 & $100 \%$ & $7 / 3(30)$ \\
\hline Kory & $\mathrm{M}$ & 8 & 7 & 4 & Yes & 843 & $99 \%$ & $30 / 16(73)$ \\
\hline Maggie & $\mathrm{F}$ & 16 & 2 & 2 & Yes & 130 & $99 \%$ & $12 / 5(30)$ \\
\hline Kyle & $\mathrm{M}$ & 17 & 6 & 2 & No & 330 & $53 \%$ & $2 / 1(26)$ \\
\hline
\end{tabular}

\section{Procedures}

Each participant was selected based on the criteria noted above and contacted via phone. In the initial phone conversation, we explained the purpose of the study and scheduled an appointment for the interview. Each person contacted agreed to participate in the study. At least two of the authors were present for each of the interviews, except one which was conducted by a single researcher. During the interview one researcher asked questions while the other took notes and monitored the recording devices.

At the start of the interview, the purpose of the study was explained, as well as the terms of participation in accordance with human subjects protocol. Each participant signed a consent form and was informed as to the research questions guiding the study: (a) How do American Indian school leaders reconcile Western educational leadership preparation with Indigenous knowledge? (b) How does this reconciliation reflect and model anti-racist educational leadership? They were then asked seven questions regarding their 
perceptions of identity as a leader, the congruity of identity with their leadership preparation, the practice of authentic leadership, the congruity of identity with their leadership practice, and how they negotiate paradigm differences in meeting the expectations of public schools and the community in which the school is situated. The seven questions were derived from the conceptual lens of the Leadership Triad described above. The meaning of what the participants experience as racism and how they experience it emerged from the conversations about identity, integrity and authenticity in regard to the context of leadership preparation and practice. The interview conversations, which averaged two hours in duration, were recorded and transcribed for analysis.

Transcripts were analyzed by each author independently creating a nonrepetitive list of significant statements made by each participant about a conflict between identity, integrity and authenticity (textual description) and how the experience happened in leadership preparation or leadership practice (structural description). Researchers independently grouped these statements into themes for each participant and across participants. Using these independently developed themes, the researchers jointly constructed composite descriptions for each participant. From these composite descriptions, the essence of the findings was co-constructed (Gorgi, 2009; Moustakas, 1994).

Member checks in which all 10 participants were given the opportunity to review the integration of their contributions throughout the manuscript were conducted, and all respondents affirmed the credibility of the findings. Triangulation occurred through the inclusion of diverse participants in terms of tribal membership, gender, leadership position and community context in data collection and through the independent identification of significant statements and themes by the three researchers in analyzing the written transcripts. Dependability was established through a consistent interview protocol used for all interviews, the use of two interviewers for 9 of the 10 interviews, and the use of an operational definition to identify significant textual and structural descriptive statements across all interview transcripts.

\section{Findings}

Three major themes emerged highlighting how these leaders address racism in their schools while creating spaces that were more conducive to the practice of culturally responsive pedagogy. The themes detail how the leaders reconcile cultural clashes and confront racism by using (a) identity, (b) relationality, and (c) re-normed practices. 


\section{Leader Identity}

The 10 participants were diverse in how they articulated their identity and how it informed their school leadership. Tribal affiliation was primary; Jake noted, "I'm a [tribal affiliation]... So that's how I was raised. So I always thought I was just a [tribal affiliation]." Also, ability with the tribal language impacted their native identity; Lucy explained, "I'm an Indian dancer...the minute my dad hit that drum, l'd dance as long as he'd play the music... and he'd tell stories, and he'd talk [tribal affiliation] to us. But I never spoke [tribal affiliation]." Whether they were raised on or off the reservation and whether they considered themselves multicultural or bi-cultural also impacted identity; as Shawna described, "I am a second generation urban Indian." The leaders' Indigeneity permeated their selfdescriptions of identity in unique ways, which corroborates Montana's IEFA Essential Understanding 2 as discussed above.

Also, connections were demonstrated between the participants' understanding of their identity and its impact on their experience in the ILEAD program; as Jake shared:

There were some who really tried to prove who's more Indian, and I think that was a result of their own identity being challenged. Because their ideas of what's acceptable as a Native were being challenged by others and by the program...I went to tribal college, and we had to verbalize what our community and culture believe, and just that was powerful.

How these Indian leaders defined their identity clearly impacted how they navigated both their westernized educational leadership preparation and their leadership practice. When asked how her identity informed her leadership, Rosie described a holistic and integrated identity,

I have to say honestly that it's present with me all the time, but I have to be very mindful of where I'm at. If I was an administrator 10 miles down the road [on the reservation], it would be different even though we're in the same school district. That river is such a significant thing to me, when I cross the [named] River here every morning... leaving your familiar surroundings. It's a hard thing to explain...it's a different approach. I have to be mindful of it. That culture, as far as mine and being a leader here, it is a big part of my everyday practice.

From this statement, we see that Rosie has integrated her identity psychologically, but the river she crosses everyday between home and work is a barrier between safety and risk. In crossing that river she wrestles with how much of her identity to reveal, how to reveal it, and when to reveal it. Racism appears not to impact her identity or integrity, but may impact her authenticity because it forces her to select when she should exercise her indigenous leadership and when she should stifle her indigenous identity. 
How these leaders held their identity varied. Kyle conveyed how context impacts how his identity is viewed by others and how the context influences how he views himself because he is of a different tribe from the majority of his students and community:

... when I'm on the rez I'm White; when I leave, I'm Indian; it's a kind of dual citizenship ...but the more I'm established here the more the fact that I'm Indian comes out. Students and the community begin to realize it more; I've heard people on the rez say, "You might be Indian but you don't know about things here."

Maggie also described the influence of context on self as facilitating adaptation as one moves across cultural boundaries, or in her words,

They notice that you're talking different and then I adapt and change back, if you will, kind of like a professional way of speaking, on a level where we're both connecting. And when I get around relatives or whatever, it comes back. So I guess it's kind of adapting, to who you're with and where you're at.

Despite a nuanced movement between Native, inter-Native, and non-Native contexts, these leaders consistently knew their identity was critical to successfully weaving in and out of these cultural settings as school and community leaders. Underscoring this, Josie noted the primacy of her Indigenous identity and its integration with her leadership role:

I'm [tribal affiliation] first, and a principal next. So a lot of things I do relate back to my [tribal affiliation] culture and traditions, and character in general. I try to bring those practices as much as I can into the school. I smudge if I can, way before everybody gets here, because talk is really a bad thing sometimes, on your spirit - on your soul.

Jake framed his integration of identity in leadership as a calling, "That's why I'm doing this...I never looked for a career...I just wanted to help my community and my tribe." His statement captures the essence of Medicine Crow's (2006) description of Indigenous leadership - a series of exemplary acts observed in everyday life aligned to tribal values.

These leaders' identity informed their authenticity which allowed them to address difficult situations surrounding race and culture within their schools - to have what Allen (2007) described as "courageous conversations." Both Rosie and Jake spoke to this regarding the schedule of the tribe's "Annual Cultural Gathering" of tribal members which happened to conflict with professional development days for teachers; Jake shared the district's response, "Can't they change the date of the [Gathering]?" Rosie added, "Finally I spoke up and contested, "The [Gathering] is always the third week of August." Jake further elaborated on this issue:

... when the school year starts, it cuts right into our [Gathering] time. A lot of people just discount it, but my thought is, seems like New Orleans works around Mardi Gras. So our [school] year starts right then, and all of 
our Native teachers are tired. And we've got to come to in-service, after putting up eight teepees and doing labor all day, you can't take your teepee down until after the Parade Dance... It's a rough time for a [tribal affiliation] Indian teacher here. I don't think we should have to choose between the two, but it seems like that's what they want. They meaning the people who create schedules. It's like, "You're a teacher, you chose to work here"... but what about $80 \%$ of our student body? They're still recovering too.

For both Rosie and Jake, some cultural clashes cannot be ignored. They felt compelled to speak against the lack of appreciation for Indigenous culture that too often comes from assumptions commonly held by those from the dominant culture. In stepping into these uncomfortable conversations, they refused to remain silent when power combined with cultural and structural racism dictated what "normalcy" was (Potapchuk, Leiderman, Bivens, \& Major, 2005).

Racism in the form of cultural clashes related to instruction occurred. Jake shared an example of this in describing an American Revolution history lesson he observed taught by one of his non-native elementary teachers. Jake mentioned to her in the follow-up conference that she might rethink how she discusses this topic in a more culturally responsive manner,

Remember, these are little Indian kids we're teaching, so don't say, "When we fought the British." Say, "When the English settlers fought the British" because it sure wasn't the kids in your classroom. If you talk about it like they're part of it, they're going to feel displaced, because it's not them.

He continued stating that the teacher was very upset and accused him of being racist against her and White people. All of these leaders discussed issues where they had to address cultural clashes between the westernized public school paradigm and their own tribal identity and leadership as they stood firmly against racism born of ignorance.

These Indigenous leaders held their identity in different ways but all claimed it as critical to their leading in Indian country. Additionally, identity was critical to their being authentic in leadership so that they could create more socially just and non-racist schooling for all of their students while maintaining their integrity as school leaders. Their willingness to take on the subtlety and pervasive nature of racism in their schools and communities also enabled them to combat within themselves further diminishment of their identity by acquiescing to racism and contributing to personal "internalized racism" (Potapchuk et al., 2005).

\section{Relationality}

Most educators would agree that caring is important if they want to work effectively with students. Geneva Gay (2010) makes a distinction between caring for and caring about students. Gay (2010) explains that caring about and caring 
for students is not only about feeling but also doing something about the feelings to help someone. Caring for students is a major component of culturally responsive pedagogy and results when teachers advocate for students. Displaying caring for behaviors in Indigenous communities can be seen in the complex dance of relationality. All interactions, starting with initial greetings and moving to elaborate storytelling, are designed to connect individuals in a relationship.

Relationships with students. These school leaders shared how they leverage relationality and serve as role models for American Indian students. Shelly commented, "I felt that my students finally have someone that looks like them and is here to represent them and stand by them." Kyle confirmed that having an American Indian lead their school is unique for American Indian students and they relish the opportunity to connect with a leader like them: "It brings a role model ... students believe, if he's done this I can do it; students will come to talk to me before they approach another teacher or the vice principal because they know l'm Native American."

Kory explained the importance of establishing and nurturing relationships for the students in their care versus a relationship based on power and hegemony.

Tyler [another American Indian leader] and I have always preached relationships between teacher and student, student to student, just getting to know kids better... a relationship can go a long way; sometimes it's as simple as talking to kids...we had a high school kid who was having some suicide issues...we talked about some things. The good thing is he has a world of support around him. I think Tyler touches on relationships all the time, even more than he touches on academics.

The relationship building goes beyond the confines of the school as highlighted by Lucy, "I'm an active [tribal affiliation] at ceremonies - I'm around - kids see it they're validated - they love seeing me in both worlds - their parents too ..." Josie explained how important her connection to students is and how being there beyond the school day reinforces ties to community, which is not common practice among non-Native teachers and principals working in schools on or near the reservations.

That's my strong point and always has been. I've always taken it upon myself to get to know my families. Try to find a connection with that student so I could teach them to the best of my ability. Every kid I know, I try to find [a connection with family]...oh, I know your grandma. I know your aunt. Oh, I taught your sister...in the morning I stand outside and greet everyone, and try to know everybody's name.

Relationships with teachers and staff. There are relatively few American Indian school leaders and teachers, yet support staff in reservation schools is often Native. Creating a welcoming environment and establishing allies helps school leaders transcend functional barriers that often exist in the hegemony between faculty and staff, especially when reinforced with racial 
differences. To gain support, Native school leaders apply their relationality with staff. Shelly emphasized the positive rapport with her secretary. "She [school secretary] and I started at the same time...So I had huge support from our school secretary. She had my back...I had her back...that was huge." Others shared the same sense of working towards a common goal and the important role relationality plays regardless of an individual's cultural identity; as Rosie stated:

It goes back to relationships again. You have to have the right individuals. Everybody has to be in the same frame of mind and they've got to be on the same path of knowing that child... that's got to be the goal. It can't be "it's my way"...it doesn't have to be a teacher that's fluent in [tribal language]. If I know there's a teacher out there that has it in their heart and has that same attitude and potential of helping that child keep who they are and enhancing that...It doesn't matter the culture, ethnicity, or race.

Relationships with community members. As mentioned above, some school leaders serve in communities they consider home whereas others come from outside the community. Each of these school leaders spoke of the challenges of serving in schools with high concentrations of American Indian students regardless of whether they were serving in communities amongst their families, clans and tribes or not. As highlighted by what Shawna said, all of these Indian leaders talked of the need for relationships and trust:

If you have a trust-based relationship with your stakeholders, you can do just about anything. It may not be pretty...sometimes we have to agree to disagree... if the relationship is there, you can make progress. If not, you don't stand a chance. But as an administrator...you have to say, "I understand what you're saying. But this is the way it has to be"... It cannot be about power...or you lose respect.

When challenging situations occur, these leaders stood strong as Shelly explained when she had to confront a parent regarding child neglect.

[He] just got his daughter back from social services, and he was going back to [his old ways with] her coming in late, with her hair not fixed, and her clothes not clean...I asked, what's going on at home...But I wasn't saying it that nice....and he said, I don't like your tone of voice... what would you rather have, me telling you the truth, with my tone, and giving you a heads up that you'd better get your act together or having social services take her away again... he was mad at me at first, but in the end, he said, I like you...Y You know why? Because you're honest... and now when he comes to the school, he's like, hey, Mrs. [S]!

As the quotes above demonstrate, American Indian school leaders have a connection with the community based on similarities in identity and lived experiences. They can relate to the personal hardships many of their students' families endure first hand; therefore, the families are willing to extend a level of conditional trust that goes beyond what they would extend to a non-Native school leader. 
Many American Indian parents do not feel welcomed in our public schools because of the legacy of forced assimilation (Klug \& Whitfield, 2003), yet school leaders still must engage all parents in a school-home partnership for the success of each child (Epstein, 2001). Shelly shared, "We want the parents to come into this school. That's one of the ways to success; you've got to involve the parents." Kory added that compassion and not brutal honesty is what is needed to build respect and a sense of community.

One thing I've learned in my eight years...it's that there's nothing wrong with being honest. Not brutally honest, like, 'you're terrible,' but sometimes you just have to have conversations... and you can't build respect or trust if you don't. It has to come from you; it can't come from them. I had a grandmother come in last week just on fire. [Her] kindergarten kid got in trouble, and she was standing right here, and just going off. Just on fire. And I know her, her family, her kids, her grandkids. We talked and worked through what the issue was. I understand; it was her grandkid. And her grandkid does no wrong. But in the end, we worked through it. I was honest and told her what I found and investigated, and I think she left not hating me...So being honest, and then comes respect. People around these parts, they've been jerked around too much, from a lot of things. So I've found that, don't lie to them. Don't beat around the bush, don't be mean in how you talk to them, and let them talk.

Sharing lived experiences and understanding the challenges many American Indian families face helped these leaders compassionately deal with circumstances that might seem very foreign to many non-Native school administrators. As Shawna self-disclosed,

It's [self-disclosure] helped a great deal in terms of developing trust with the families...I have an understanding for what Native life is like in terms of identity and culture and what it means; family, extended family. And in terms of what they're dealing with in crisis, whether it's substance abuse or whatever - I have a lot of grandparents raising grandkids because the parents are unavailable... and when they get a feel for the fact that I've been where they are....when they realize I've experienced some of what they're dealing with, it helps immensely.

Clearly, these leaders recognize the critical integration of their identity and integrity and authenticity as they serve not just their schools but serve as significant leaders for their entire communities.

Relationships with fellow administrators. American Indian school leaders in the past have felt isolated, unsupported and without voice. Even though currently American Indian school leaders may be the only Native leader in their school and/or district, they are now a part of a statewide network of American Indian school leaders. Being part of the ILEAD cohort has provided this network of sustained support. Shelly shared,

Being able to trust the people that you're with, going to school, was a huge aspect of success in the program. Because they knew exactly the 
types of issues we deal with...and how you deal with them. And being able to vent to your peers as well, and knowing that's not going to go anywhere [else]...they know the frustrations you're going through.

Shelly went on to discuss how this network is used to improve the hiring of staff in Indian schools,

What you do is you get on that phone and you call [ILEAD colleagues] and you ask, what's this person like? That's huge. You are open and honest, and that was one thing with ILEAD - people remember you...so you still see those people and call each other.

Several of the leaders commented how ILEAD enabled them to build connections. Kory commented, "Being in the program and seeing quite a few administrators - home-grown Indian administrators - who are still doing work in rez schools...we've made connections and share stories." These thoughts were supported by Shawna.

I call someone in ILEAD and say, guess what happened yesterday? And they say, oh yeah, that happened to us last year. Let me tell you how we handled that. Otherwise you're completely isolated. So it's a critical piece. It helps you keep your sanity, and it reminds you why you're doing what you're doing, and that you're not alone.

\section{Using Indigenous Awareness to Re-norm Practice}

Throughout communities in the United States, a primary role for school administrators is implementing policies established by school boards, state and federal officials, and on Indian reservations by tribal councils, as well. A critical difference among all school leaders is how the leader interprets policy and establishes the norms that support policies (Ruff \& Geiselmann, 2012). Many of the American Indian school leaders in this study stated their identity was used in interpreting policy and establishing Indigenous-friendly norms through daily decision making. Kyle stated:

We follow the letter of the law because that's what we do. But our procedures sometimes have to be outside the box. We have to be willing to accept some unconventional ways of making things work...that in Indian country, a funeral might take 2 weeks, and not dropping a kid on the tenth day...[because] they're accounted for, and they will come and make up the work.

Ruff and Geiselmann (2012), using a nation-wide qualitative database (Voices III), found that school leaders' daily decision making tended to focus on childcentered needs as opposed to accountability-oriented goals. As a result, Kyle's statement aligns well with what principals do across the nation. Similarly, Cathy addressed how the integration of her identity and leadership practice facilitated high expectations, "I can empathize with what they've [American Indian students] 
gone through, I can understand, show them that you need high expectations, you need to rise to this level." Maggie explained the give and take nature in negotiating the expectations and that sometimes it is the policy that must change.

At basketball games, your ears are going to be full: "They don't understand," etc. So I hear all sides. I find myself connecting with both actually... we've had to amend our policy to say, ok, well, these are excused absences ...that's the community and parents telling us that.

Conversely, Jake clarified the importance of leadership in maintaining accountability by saying, "I think there are people who use [excuses] as a crutch, to not be held accountable. But our big responsibility is to the children of our tribe. So we can't use those crutches anymore."

As the above examples demonstrate, there are many similarities among school leaders who seek to contextualize policies and leadership theories to their communities and their children. What is different within the American Indian context is how the schools are situated. The American Indian school leaders in this study worked in schools that serve American Indian communities in which a majority of students are American Indian yet the majority of teachers are nonnative. Indigenous culture is sandwiched by Western culture at two levels. At the micro-level there is a layering of complexity where a teaching corps of predominantly White teachers is sandwiched between American Indian students and American Indian school leaders. At the macro-level, the American Indian community, with a worldview incommensurate to mainstream American culture, is sandwiched between the dominant colonizing culture and the local public school system, a westernized institution. And it is in this layering that racism is most pronounced. Yet, the lived experiences of these leaders reflect a layering that is less distinctive and more marbled through their use of identity, integrity and authenticity. Furthermore, the ways these leaders demonstrate their authenticity in reconciling the cultural clashes seem to further marble the layers.

In looking at the macro-level, Shawna described the clash between the school and the state:

We look at individual progress. [The] state doesn't do that. They look at, is the child proficient? Have they met the state standards? Our kids don't meet those standards...we did the pilot of the Smarter Balance testing. I had kids crying, heads down, crying.

Shawna's description demonstrates the impact of institutional racism in a very clear and vivid picture regarding its effect on children. What is not as explicit is that this impact is enhanced by the Indigenous value of relationality. In other words, the "kids crying" is likely more due to the child's relationship with the school and their inability to meet the expectations of that relationship than mere frustration in the experience of test taking. In the context of the culture, the institutional racism is more insidious as it deteriorates the relationships among the school leader and teachers and the students, as well as the school as an institution. 
Shelly described how a clash between the school board and the community required transparency in governance.

I don't think the two [board and community] had a very good relationship, because of past board decisions...I truly believe that we've come a long way, with developing good relations. But you have to be transparent to your community and let them know what's happening in your school.

Again, the primacy of relationality emerges in the context of modeling anti-racism in schools in the form of establishing and maintaining relational trust between the school leaders and community members.

Kory further articulated how the parents' and school's expectations clash.

The unwritten language of what Indian parents want the school to do for their kids... really clashes with the importance the school puts on grades and attendance, [parents] send their kids to us, every day, to be cared for...that's one of the things that they're telling us without telling us.

In this statement, Kory identifies the nature of the clash between the values held by the schools and federal policies on the one hand-meritocracy—and what the community values on the other hand-relationality.

In looking at the micro-level, Linda conveyed the clash between the nonNative teachers and the experiences of their students, "The conduit between understanding the families [is] understanding hunger, poverty, [but] my nonIndian teachers have no understanding. The reason my seventh and eighthgrade boys get so cantankerous at about 9:15 is they haven't been able to get enough breakfast." In this example, the teachers are not attending to relationship with their students. Yet, Shawna shared an example of how the layers are marbled despite a racial clash. Specifically, students will talk about teachers demeaning them for their race. Shawna confronted them, "What does it mean to you to be Indian? They don't have an answer. The one who usually starts talking to them about it is Anna, our school board member, who's non-Native, because she knows more about their history than they do." Anna modelled a way for the teachers to establish relationship by learning about the community, its culture and its history. Similarly, Jake described how the clash between cultures was blurred.

One little kindergartner said, Ms. [P], what kind of Indian are you? And she laughed and said, I'm a White lady. And he said, No you're not - for real, what kind of Indian are you? ... I [Jake] think Indian people, when they say "White," they don't really mean race. They mean a way of being. Are you just going to dominate others and feel like you're right and everyone else is wrong or be more connecting and respectful? Ms. [P] believed in relationships, because years later, she still checks on those kids she taught.

In his story, Jake captures the essence of what relationality means and how it can be expressed by a teacher. Ms. P., the heroine of the story, is a leader 
whose exemplary relationship with this student aligns with his tribe's highest values-relationality —and thus making them "Indian."

Finally, Rosie articulated how relationship building must remain paramount in addressing racism despite how painful a situation becomes. The leader must rise above the toxic conditions to confront the situation openly, honestly, and hopefully.

I had this talk with the staff that I'd been thinking about all spring... I looked at a couple individuals and right away these negative thoughts came into my mind: things that had been published, I could see the anonymous letters right in my mind, the things they'd called me, the accusations, things that were blatantly false. Then I suddenly looked over and saw a couple of the ladies that are so supportive, and one of them, her eyes - I just felt for her. I said [to the staff], "I am from here, and I know many of you, and I went all through my schooling here. My aunt lives down the road, my grandmother lives over here; this is where I come from. [This year] It's really tested me about who I am, as a leader, educator, parent, community member. I've explained and justified myself to the board, because I was directed to. It was hard, but what it showed is that we have such a big capacity here in this building, and it's redefined that so much I feel pretty good that everything we have - we're ready to take off. I'm talking about every one of you here and your part. [I also told them] that those letters were very malicious, hurtful, disrespectful... down to the color of my skin." I had to say it and get it out there. Otherwise it's just unspoken, and that can't be because we're dealing with kids, who come from different ethnicities. ... I went home that night and went to bed, and I know I said the right thing. I had to say it.

By remaining true to her identity and integrity, Rosie found the courage to be authentic in a hostile environment. It was through this authentic leadership that she was able to create awareness of racism. Through the awareness comes change toward non-racist schooling.

\section{Implications and Conclusion}

Three major themes emerged linking the Leadership Triad (Henderson, 2007), these leaders' preparation, and their anti-racist practice. The leaders' identities enabled them to enhance the experiences of their students and their school systems in contrast to the colonizing racism of Western schooling which often diminishes the identity of American Indian students and entire communities (Klug \& Whitfield, 2003). From this deep embracing and use of their identity, authenticity emerged, resulting in uncommon relationality (Wilson, 2008). Their authenticity and relationality enabled them to re-norm practice to minimize cultural clashes. Their leadership softens the cultural contrasts to marble the contrasting layers. 
Complex cultural clashes demanded a level of self-awareness and authenticity from these leaders that challenged them to ask fundamental questions about what they must do to serve their students and their communities. Kory's comment that what Indian parents want the school to do for their kids is care for them and that this trumps academic achievement is an example of these complex cultural clashes. The Native community is seeking relationality whereas the school as an institution of the colonizing dominant society seeks academic achievement. These courageous leaders faced nuanced and marbled contexts without cynicism or defeat but with grace and resolution in order to protect their students, families and communities from further annihilation of their identity through cultural assimilation.

These leaders' practices made a significant impact in their schools although the results did not fit into a westernized framework of Adequate Yearly Progress (AYP)-type accountability (à la No Child Left Behind, 2002). Relationships undergirded everything these school leaders did; intentional confrontation of cultural clashes using Indigenous relationality as the grounding for these exchanges was paramount. In doing so these leaders refused to sweep racism under the rug but were willing to step into courageous conversations (Allen, 2007), modeling an integrity that encouraged their staff to honor the identity of Indian children within the dominant society's school system as Rosie demonstrated in her end-of-the-year address to her teachers. Was culturally responsive pedagogy the norm? Perhaps not. But these leaders were opening the door for culturally responsive pedagogy to become a reality in these schools. Kory suggested that the ILEAD program had initiated this process:

I don't think you guys at the university will ever understand the road that you are paving for schools and administration and leaders that are Indians...you're giving reservation schools a voice. We just used to be a black eye for the state - that's how we felt...l find it nothing short of amazing how much the university itself has listened, more than anything. We've always felt, as a reservation school, different - but now we're being recognized for that.

Rosie revealed the sensitivity these leaders bring to their responsibility to lead schools so that they will become places where all children's, but especially Indian children's, identities are not diminished but enhanced. Describing her dream school, Rosie articulated:

When that kid comes through the structure of the public school system, and it's so rigid... we're trying to form that kid. And it shouldn't be that way; it should be that the kid comes to us with her/his authentic education. And this school should be mindful of where that kid came from, and the kid should come out still like this, but even more.

All of these leaders face this cultural clash of seeing Indian children shaped by their schooling too often in ways that take from their identity rather than enhance it. These leaders recognize this diminishment of Indian children's identity because they experienced it in their own lives. Ultimately, confronting racism 
demanded that these leaders connect with those who are different from them; racism suffocates under the weightiness of relationship with others.

\section{References}

Allen, J. (2007). Creating welcoming schools: A practical guide to home-school partnerships with diverse families. New York, NY: Teachers College Press.

Bird, C. P., Lee, T. S., \& Lopez, N. (2013). Leadership and accountability in American Indian education: Voices from New Mexica. American Journal of Education, 119(4), 539-564.

Carjuzaa, J., \& Fenimore-Smith, K. (2010). The give away spirit: Reaching a shared vision of ethical indigenous research relationships. Journal of Educational Controversy, 5(2). Retrieved from http://www.wce.wwu.edu/ Resources/CEP/eJournal/v005n002/a004.shtml

Deloria, V., Jr., Deloria, B., Foehner, K., \& Scinta, S. (1999). Spirit \& reason: The Vine Deloria, Jr., reader. Golden, CO: Fulcrum Publishing.

Epstein, J. L. (2001). School, family and community partnerships: Preparing educators and improving schools. Boulder, CO: Center on School, Family and Community Partnerships.

Faircloth, S. C. \& Tippeconnic, J. W. (2013). Leadership in Indigenous education: Challenges and opportunities for change. American Journal of Education, 119(4), 481-486.

Gardner, J. W. (1990). On leadership. New York, NY: The Free Press.

Gay, G. (2010). Culturally responsive teaching: Theory, research, and practice, ( ${ }^{\text {nd }}$ edition). New York, NY:Teachers College Press.

Gorgi, A. (2009). The descriptive phenomenological method in psychology: A modified Husserlian approach. Pittsburg, PA: Duquesne University.

Grahn, J. L., Swenson D. X., \& O'Leary, R. (2001). A comparative analysis between American Indian and Anglo American leadership. Cross Cultural Management, 8(1), 3-20.

Henderson, D, Ruff, W. G. \& Carjuzaa, J. (In press). Social justice leadership for American Indian sovereignty: A model for principal preparation. Journal of Education and Social Justice.

Henderson, D. (2007). The leadership triad: Identity, integrity, authenticity. Unpublished dissertation, Missoula, MT: The University of Montana.

Hohepa, M. K. (2013). Educational leadership and Indigeneity: Doing things the same, differently. American Journal of Education, 119(4), 617-631. 
Jaime, A. M. (2008). Native women: Decolonization and transcendence of Identity. International Journal of Multicultural Education. 10(2).

Kirkness, V. J., \& Barnhardt, R. (1991). First nations and higher education: The four Rs-respect, relevance, reciprocity, responsibility. Journal of American Indian Education, 30(3), 1-10. Retrieved from http://jaie.asu.edu/v30/V30S3fir.htm

Klug, B. J. (Ed.). (2012). Standing together: American Indian pedagogy as culturally responsive pedagogy. Lanham, MD: Rowman and Littlefield Education.

Klug, B. J., \& Whitfield, P. J. (2003). Widening the circle: Culturally relevant pedagogy for American Indian children. New York, NY: RoutledgeFalmer.

Kovach, M. (2009). Indigenous methodologies: Characteristics, conversations, and context. Toronto, Canada: University of Toronto Press.

Marshall, J. M. III (2009). The power of four. New York, NY: Sterling Publishing Inc.

Medicine Crow, J. (2006). Counting coup: Becoming a Crow chief on the reservation and beyond. Washington, DC: National Geographic.

Moustakas, C. (1994). Phenomenological research methods. Thousand Oaks, CA: Sage.

Mont. Code. Ann. ttl. 20, ch.1, pt. 5, § 1. Indian Education for All. 1999

Mont. Const. art. X, §1.

Montana Office of Public Instruction (OPI). (2014). Montana American Indian student achievement data report. Retrieved from http://opi.mt.gov/ pdf/IndianEd/Data/14INEDStudentDataReport.pdf

Palmer, P. (2000). Let your life speak. San Francisco, CA: Jossey-Bass.

Palmer, P. (2004). A hidden wholeness: The journey toward an undivided life. San Francisco, CA: Jossey-Bass.

Potapchuk, M., Leiderman, S., Bivens, D., \& Major, B. (2005). Flipping the script: White privilege and community building. Silver Spring, MD: MP Associates, Inc. and the Center for Assessment and Policy Development (CAPD).

Ruff, W. G. \& Erickson, J. L. (2008). Contextualized principal preparation for the improvement of American Indian education: Negotiating cross-cultural assumptions. In Papa, R. (Ed.), Leadership on the frontlines: Challenges in preparation and practices (pp. 244-254). Lanham MD: Rowman and Littlefield.

Ruff, W. G. \& Gieselmann, S. (2012). Growth and development of children. In M. Acker-Hocevar, J. Ballenger, A. W. Place \& G. Ivory (Eds.) Snapshots of school leadership in the $21^{\text {st }}$ century: Perils and promises of leading for 
school justice, school improvement, and democratic community (pp. 3154). Charlotte, NC: Information Age Publishing.

Thompson, C. M. (2000). The congruent life. San Francisco, CA: Jossey-Bass Publishers.

Weber, M. (1946). From Max Weber: Essays in sociology. (Gerth, H.H. and Mills, C.W. Eds/Trans.) New York, NY: Oxford University Press.

Wilson, S. (2008). Research is ceremony: Indigenous research methods. Halifax, Canada: Fernwood Publishing.

Writer, J. H. (2008). Unmasking, exposing, and confronting: Critical race theory and multicultural education. International Journal of Multicultural Education. 10(2), 1-15.

\section{Author Contact}

David Henderson (corresponding author): david.henderson3@montana.edu Montana State University, Educational Leadership, 112 Reid Hall, Bozeman, MT 59717-2880, U. S. A.

Jioanna Carjuzaa: carjuzaa@montana.edu Montana State University, Education, 119 Reid Hall, Bozeman, MT 59717-2880, U.S. A.

William G. Ruff: wruff@montana.edu Montana State University, Educational Leadership, 113 Reid Hall, Bozeman, MT 59717-2880, U. S. A. 